\title{
Study of Tetraethylammonium bis(trifluoromethylsulfonyl)imide as a Supporting Electrolyte for an All-organic Redox Flow Battery Using Benzophenone and 1,4-di-tert-butyl-2,5-dimethoxybenzene as Active Species
}

\author{
Xiang Wang ${ }^{1,2}$, Xueqi Xing ${ }^{1,2}$, Yongjie Huo ${ }^{1,2}$, Yicheng Zhao ${ }^{1,2}$, Yongdan Li $^{1,2,3}$, Hong Chen ${ }^{4, *}$ \\ ${ }^{1}$ State Key Laboratory of Chemical Engineering (Tianjin University), Tianjin Key Laboratory of \\ Applied Catalysis Science and Technology, School of Chemical Engineering, Tianjin University, \\ Tianjin 300072, China \\ ${ }^{2}$ Collaborative Innovation Center of Chemical Science and Engineering (Tianjin), Tianjin, 300072, \\ China. \\ ${ }^{3}$ Department of Chemical and Metallurgical Engineering, School of Chemical Engineering, Aalto \\ University, Kemistintie 1, FI-00076 Aalto, Finland \\ ${ }^{4}$ School of Environmental Science and Engineering, Tianjin University, Tianjin 300072, China \\ *E-mail: chenhong_0405@tju.edu.cn
}

doi: $10.20964 / 2018.07 .56$

Received: 12 March 2018 / Accepted: 8 May 2018 / Published: 5 June 2018

\begin{abstract}
An ionic liquid tetraethylammonium bis(trifluoromethylsulfonyl)imide (TEATFSI) is synthesized as the supporting electrolyte in an all-organic redox flow battery system with acetonitrile as the solvent. Benzophenone (BP) and 1,4-di-tert-butyl-2,5-dimethoxybenzene (DBB) are used as the redox active species. The battery exhibits a high open voltage of $2.95 \mathrm{~V}$. The electrode reactions are controlled by diffusion, which is significantly influenced by the cations of the supporting electrolytes. With TEATFSI as the supporting electrolyte, the diffusion coefficients are $1.21-1.43 \times 10^{-5} \mathrm{~cm}^{2} \mathrm{~s}^{-1}$ and 0.89 $1.16 \times 10^{-5} \mathrm{~cm}^{2} \mathrm{~s}^{-1}$ at anode and cathode, respectively. The coulombic, voltage and energy efficiencies of the battery are $97 \%, 46 \%$ and $44 \%$, respectively. The battery shows a stable performance during 50 charge-discharge cycles.
\end{abstract}

Keywords: All organic redox flow battery, Ionic liquid, Energy storage, Supporting electrolyte, Tetraethylammonium bis(trifluoromethylsulfonyl)imide 
(C) 2018 The Authors. Published by ESG (www.electrochemsci.org). This article is an open access article distributed under the terms and conditions of the Creative Commons Attribution license (http://creativecommons.org/licenses/by/4.0/). 